\title{
EM DIREÇÃO À AUTENTICIDADE: ENCONTRO COM A DIFERENÇA
}

Graham Price

\begin{abstract}
RESUMO: Este artigo apresenta reflexões sobre um estudo de caso, na Nova Zelândia, de um curso de Arte em uma classe de alunos de sete a nove anos. Investiga a motivação e os resultados gerados por um trabalho em equipe, que usa a arte como base de integração para um exame histórico, social e pessoal. Levanta questôes sobre como professores de uma cultura dominante, e seus jovens alunos, podem se abrir às referências indígenas presentes na cultura de seu país e criar, com elas, um autêntico vínculo pessoal. Procura ilustrar algumas tensões geradas pelo papel tradicional do professor "controlador" e "detentor do conhecimento", revelando a face sutil da autoridade ilegítima. Como fazer com que a arte na escola abra espaço para que as crianças possam realmente se expressar e não apenas seguir à risca as indicaçóes e diretrizes de seus respectivos professores? As respostas podem estar na maneira como os professores também se arriscam a serem autênticos, buscando suas referências histórico-culturais e as que se encontram nos arredores da escola.
\end{abstract}

Palavras-chave: Arte. Educação. Relação professor-aluno. Autoria. Multiculturalismo.

Tradução de Ana Angélica Albano. A apresentação oral deste artigo, em inglês, foi realizada pela primeira vez durante a $15^{\text {th }}$ National Conference of the Australian Institute of Art Education (Cairns, junho de 1995).

** Artista plástico, professor de Arte Visuais e Ensino da Arte na Educação da Faculdade de Educação da Universidade de Waikato (Nova Zelândia). E-mail: grahamp@waikato.ac.nz 


\title{
TOWARDS AUTHENTICITY: MEETING WITH DIFFERENCE
}

ABSTRACT: This paper presents reflects on the case study of an art unit in a class of seven- to nine-year-olds, in New Zealand. It examines the motivation and outcomes generated by team teaching using art as the primary means of integration to explore personal and social history. It raises questions as to how teachers within a dominant culture can open themselves and their young students to suppressed indigenous histories and draw an authentic personal connection to them. The paper seeks to illustrate some underlying tensions around the notions of 'control' and 'knowledge holder' embedded within teachers' traditional roles and to raise the subtle face of illegitimate authority. In school settings, noted for rewarding students for compliance to the teacher's initiative, how might art experiences lay open the ground for children's authentic work to emerge? The answers appear to be found in the relational, where the teacher also risks being authentic in meeting with the cultural histories situated near the school's physical environment.

Key words: Art. Education. Teacher-student relationship. Authorship. Multiculturalism.

\author{
Ouça comigo \\ O som do canto do Tui \\ Voando ao longe \\ Tui tui tuia \\ Em uníssono com o que está acima \\ Em uníssono com o abaixo \\ Em uníssono com o interno \\ Em uníssono com o externo

\section{Tui tui tuia} \\ Faça paz com a noite \\ Una-se a ele \\ Ouça comigo. ${ }^{1}$
}

uando estou em paz (whaka Rongo) em um lugar dentro de mim, você pode chamá-lo de ponto central entre o acima (inspiração) e o abaixo (fundamentação), entre o mundo interno e o externo, consciente da interconexão entre todas as direções então, eu estou na presença de au (self em maori), talvez $A u$, Aurum (o 
ouro do alquimista). As ações que surgem a partir deste lugar serão fluidas, confiantes e benéficas à vida a minha volta.

Este artigo é a respeito de autenticidade, que curiosamente começa com $A u$. Autenticidade, para mim, é reconhecida pelo ouro que contém. Um lugar onde o self se apresenta alto e brilha. Como a autenticidade pode se manifestar em uma sala de aula e que papel tem a arte no desenvolvimento deste objetivo? Com que propósito a arte é apresentada na sala de aula? Uma disciplina a ser adquirida por ela mesma ou para ampliar objetivos centrados na criança e no tipo de sociedade na qual queremos viver?

Há um desafio real no encontro com outras culturas vivas no ambiente escolar. Qual cultura apresentar e por quem? Comportamentos e atitudes culturais apropriadas (apropriadas para quem?) e qual a metodologia? Neste artigo, comecei usando a voz, as imagens e a tradição de outra cultura como prefácio para o meu discurso. Isso inibiu ou facilitou a aprendizagem? Para quem? Será este um ensino apropriado ou o ensino de uma apropriação?

Se, em minha sala de aula, eu não me manifesto em relação a outras tradições culturais, meu silêncio proclama, em alto e bom tom, minha própria arrogância cultural. Se atuo a partir de uma base cultural diferente da minha, corro o risco de agredir e desqualificar, através de um conhecimento apenas parcial, a própria cultura que desejo respeitar. Não há maneira de evitar este dilema, exceto através de uma ação baseada na integridade pessoal e na consulta direta às outras culturas. A tentativa de circundar o assunto, assumindo uma supersensibilidade e excesso de tato, é, de fato, outra forma de arrogância cultural. Sou tão poderoso que se der uma resposta imprecisa para as crianças, vou por abaixo toda uma cultura e prejudicar o entendimento da criança pelo resto da vida? Acredito que culturas e crianças são mais resilientes do que isso. Seria mais convincente admitir que me arrisco, quando exponho minha própria necessidade de aprender. Que alegria para meus alunos verem que o professor continua aberto para participar da aprendizagem - tropeça nos desafios exatamente como eles.

Lembremos que a arte de outra cultura é o resultado de uma mente adulta trabalhando no mais alto e sofisticado nível de treinamento. O estilo e a forma da arte adulta que é, frequentemente, copiada nas salas de aula podem não ser o ponto de partida mais acessível 
para a criança. Este artigo argumenta que o ponto de partida mais acessível é o entendimento e a possibilidade de compartilhar a função que aquela manifestação artística preencheu, e não simplesmente copiar a forma final. Assim, eu retorno à autenticidade como a chave para uma participação saudável em outras formas de arte. Encontramos a novidade e a diferença no outro quando estamos conscientes e somos verdadeiros em relação à nossa própria experiência.

Eu passei três semanas, como professor visitante, na Escola Macandrew Bay, Dunedim (Nova Zelândia), na classe de Robin Murray com crianças de 7 a 9 anos. Numa unidade de estudo integrada, usando linguagem, arte Maori, canto, história local e pintura, tivemos como foco a busca de nossas próprias vozes, a voz autêntica. O que sublinhava e conectava os temas eram a autoridade ilegítima e a identidade pessoal e cultural. Queríamos, Robin e eu, em minha avaliação diária, examinar de que modo podíamos ensinar as crianças a se tornarem autores.

Registro aqui a visão de Robin:

O currículo invisível flui sob todo o outro currículo. O conteúdo do currículo invisível tem valor próprio, responsividade, parentesco, envolvimento e energia. Estes valores têm sido ignorados pelas iniciativas curriculares, porque são dinâmicos, subjetivos e difíceis de quantificar. Eles não podem ser apenas "permitidos" ou ter "um espaço" dado pelo professor. Professores sabem quão importante é ajudar as crianças a reconhecerem e expressarem sua própria realidade. Isso envolve confiança e aceitação da parte do professor. Isso envolve permitir que estes valores venham à tona e sejam reconhecidos, para que os conceitos ganhem forma e se desenvolvam. O currículo oficial tornar-se-á, então, o veículo de algo muito mais profundo e mais significativo, o desenvolvimento de jovens pensantes, conscientes e responsáveis.

Infelizmente, alguém poderia perguntar, então, se as aulas de arte têm um papel na supressão destas riquezas. Se quisermos desenvolver independência e interdependência na sala de aula, nós precisamos reconhecer, verdadeiramente, quando nossas ações, como professores, sutilmente erodem isso, mesmo na arena individualista da arte centrada na criança. Um programa de arte, no qual os conteúdos são sempre determinados pelo professor, é feito para desencorajar o surgimento de trabalhos autênticos. 
"Eu fiz o que você disse professor... e você me elogiou. Eu vendo o ouro da minha própria experiência e do meu próprio entendimento, em troca de merecer os centavos da sua aprovação". A autoridade tão útil para manejar uma classe pode, facilmente, subtrair a permissão para as crianças terem suas próprias ideias. Estou tentando caminhar em direção ao encorajamento de comportamentos, tais como: Eu concordo com você; muito mais do que: Eu vou seguir cegamente ou fugir de...

Um programa de arte que não dê espaço para a expressão independente das crianças encoraja a adoção do gênero "Escola de Arte" (a visita à escola, a natureza morta, o monstro...). É arte porque a organização e o material, sempre limitados, são cuidadosamente controlados pelo professor? Quando são dadas oportunidades para a independência, os trabalhos realizados merecem a mesma atenção daqueles que foram feitos sob a direção do professor? E como podemos guiar e encorajar as crianças de uma maneira que não crie e sustente dependência?

Primeiro, precisamos reconhecer e nomear o que está acontecendo. Quão frequentemente você escuta o seguinte: $E$ isto o que você quer? Eu já terminei. O que eu faço agora? Isto está certo? Como você faz marrom? Estas são perguntas que, vindas de uma criança, devem soar como campainhas de alarme. Essa forma de dependência não é inata nas crianças. É treinada! Estes padrões podem ser quebrados, devolvendo as questôes para a criança: Como você sabe se terminou seu trabalho? O que você pensa que é necessário fazer agora? Esta é uma pergunta interessante como você poderia fazer marrom?

Contudo, tais perguntas vindas de um professor podem, frequentemente, apenas levar a um jogo mais sofisticado de "Intuir o professor". Ele não está me dizendo, por que eu devo adivinhar o que ele realmente quer? Se eu adivinhar o modo certo, ele vai gostar mais de mim. Isso pode formar toda uma geração de leitores incrivelmente atentos às expectativas dos adultos, conformados com os professores ou com seu grupo de amigos, mais do que aprendizes curiosos, autoconscientes e confiantes. Eu posso sinalizar desaprovação ignorando perguntas inapropriadas, mas estou ainda sendo reativo. Se reflito sobre como a tarefa foi apresentada, posso descobrir que estabeleci, de maneira sutil, uma expectativa de dependência. $O$ professor pode saber como a pintura deve ser, mas é a criança que tem de descobrir. $O$ equívoco não está no problema apresentado, mas onde a criança pensa que a solução 
pode estar. (O professor é um dedo apontando para a lua... a criança olha para o dedo!).

Com atividades de observação, num ambiente visualmente rico, redirecionando a atenção das crianças para os aspectos visuais do mundo delas, removemos a necessidade de um adulto mediando a experiência. Ambos, criança e professor, compartilham o mesmo foco de visão, e as perguntas importantes que surgem da vontade das crianças de investigar mais profundamente o foco escolhido podem, então, ser estruturadas.

No reino da imaginação, muitos professores de arte sentem que precisam evitar este dilema. O imaginário não pode ser considerado falso porque a imagem não é compartilhada. Como professor, eu não posso entrar na cabeça da criança, portanto estou isento de qualquer preocupação com a autenticidade. Quantos monstros de olhos esbugalhados eu tenho que aceitar antes de demandar uma resposta mais rica? Eu acredito que a imaginação, verdadeiramente comprometida, não se expressa através de frágeis clichês. É verdade que, como professor, você não pode desafiar a natureza de um evento imaginado, mas pode desafiar a criança a dar-lhe mais vida... aprofundar a interpretação, explorar qualidades, fazer escolhas de acordo com o sentimento que a experiência sinaliza. Podemos apoiar as crianças a reconhecer o que elas querem fazer em arte e dar suporte para suas dificuldades?

Como professor visitante, eu tinha a responsabilidade de deixar claro como pretendia me fazer disponível para as crianças. Este papel iria mudar, quando eles aceitassem mais responsabilidades. Inicialmente, na classe de Robin, propus algumas experiências dirigidas, nas quais as crianças demonstraram que sabiam como misturar cores (inclusive marrom!) para criar a superfície de uma "pedra", usando os dedos, com uma paleta limitada de cores. Não havia preocupação com a forma. Isso havia sido planejado para evitar preocupaçôes com a exatidão da forma e possibilitar que eu conhecesse seus hábitos de trabalho. As crianças despenderam 50 minutos absorvidas, explorando misturas, conversando umas com as outras sobre as cores e texturas das pedras.

Eles consideraram que tinham terminado quando o papel estava preenchido e desfrutaram (ou não), de acordo com o temperamento, estar com as mãos lambuzadas. Eles foram solicitados a perceber não apenas o que estavam fazendo, isto é, serem capazes de repetir a seleção 
de cores e gestos intencionalmente, mas, também, como estavam se sentindo enquanto pintavam. Isso foi feito com a intenção de torná-los atentos e conscientes do próprio processo. Eu circulava com tinta fresca e fazia comentários mínimos, apenas para reforçar o envolvimento deles com a tarefa.

O próximo passo era chocar as crianças, explorando suas respostas à "autoridade ilegítima". Esta era uma classe "boa", um grupo onde $95 \%$ dos alunos se adaptariam às expectativas da professora por $80 \%$ do tempo. Se eu pretendia explorar a independência e a autenticidade, tinha que saber se as crianças iriam sentir que era permitido discordar da autoridade, que era, de fato, esperado que seguissem seu próprio senso de retidão. Solicitei, então, que destruíssem o que eles haviam amado fazer. Pedi que eles amassassem suas pinturas.

Embora a maioria das crianças tenha se adaptado rapidamente à dança da destruição, o ultraje inicial era claro e deixou uma onda de confusa excitação. Tivemos, assim, uma excelente oportunidade de discutir como nos sentimos quando seguimos alguém, contra nossa vontade. Isso serviu, também, para traçarmos um paralelo, explorando os muros do Porto, onde as crianças brincavam diariamente, mas que tinham pouca ideia de sua história.

Os muros do Porto de Dunedim foram construídos por prisioneiros Maori, residentes em Taranaki, cidade portuária de Parahika, entre 1869-1880. Sua resistência passiva à apropriação ilegítima de suas terras, arando um único sulco através dos limites "ilegais" de demarcação de território, era recompensada com prisão sem julgamento. Em 1869, homens e jovens foram presos por sua participação na oposição às forças governamentais em Taranaki e 74 foram mandados para o sul de Dunedin. 62 deles receberam sentenças de três anos e 12 receberam de sete anos de serviço penal forçado por "alta traição". Eles foram mandados para trabalhar na construção de estradas e outros lugares públicos em volta de Dunedin, incluindo o paisagismo do Jardim Botânico e o prédio numa ladeira erma e exposta do outro lado da enseada de Anderson Bay. 18 prisioneiros morreram, um deles poucos minutos depois de entrar na cadeia de Dunedin, cinco nos primeiros quatro meses, incluindo um rapaz de 17 anos. Oito anos mais tarde, em agosto de 1879, um segundo grupo de 46 "homens do arado" de Parihaka veio para a prisão de Dunedin, seguidos por mais 91 prisioneiros sem 
julgamento, em janeiro de 1880. Túneis foram escavados nas encostas de pedra e os prisioneiros eram arrebanhados para dentro deles, quando eram obrigados a passar a noite perto do lugar onde trabalhavam (Scott, 1975; Griffiths \& Goodall, 1980).

Foi neste lugar que as tribos Taranaki e Kai Tahu colocaram o monumento de pedra Rongo (Paz), com suas espirais esculpidas, encontrado em Taranaki por Tom Ngatai e Sonny Waru. As lembranças tangíveis desta história são os muros na praia ao pé da Escola Macandrey Bay. Enquanto eu trabalhava com as crianças, um grupo de jovens detentos Maori, submetidos a trabalhos forçados, estava trabalhando na manutenção deste muro e pareciam orgulhosos dos elos que haviam descoberto. Quão longe foram as mudanças em nossa sociedade?

Transformamos, então, nossas pinturas amassadas em pedras e construímos nosso próprio muro - um muro de sentimentos e proteção. Com cada pedra do muro as crianças eram questionadas a identificar o que elas estavam protegendo. As crianças escreveram: Minha pedra protege...

\section{O povo e a terra.}

A mim quando estou de mau humor.

Meu quarto e impede a entrada da minha irmã.

Afasta os sentimentos ruins de outras pessoas.

Afasta pessoas mandonas e protege meus sentimentos.

Meus sentimentos felizes e afasta a solidão.

A terra da erosão e os meus sentimentos fortes.

As crianças haviam entrado no que chamei de estado metafórico. Metáfora aqui não é tanto uma figura de linguagem, quanto a vontade de trazer o mundo interno para a identificação com o mundo externo. Aquilo que um psicólogo chamaria de "identificação projetiva”. Se entramos conscientemente neste estado, a projeção se torna uma ferramenta útil para aprendermos mais sobre nós mesmos e sobre os outros; e é, realmente, uma das portas para a imaginação.

Nosso muro de sentimentos era o primeiro produto a ser apresentado, depois que as crianças grudaram e arranjaram as pedras em grupos. Este era um marco da importância de cada um de nós, um elo 
com as memórias da resistência passiva dos Maori de Parahaka em 1870 e com nosso ambiente cotidiano. E um lembrete de que $o$ Sr. Price pode nos pedir para fazer coisas estranhas e que devemos seguir nossas próprias ideias. Como produto, era característico da "imagem dirigida pelo professor", embora eu não tivesse ideia da forma específica que obteríamos no final. Entretanto, eu sabia que iríamos construir um muro e a maneira como as crianças seriam manipuladas para produzi-lo. Isso não é necessariamente deseducativo, apenas não muito próximo do caminho do aprendizado independente da arte... ainda.

Não é apenas uma questão de escolha independente do tema, uma vez que isso poderia facilmente ser retificado. É a respeito, também, de conhecer o próprio ponto de vista, selecionando um foco pessoal dentro do assunto escolhido. Aqui eu segui o exemplo apresentado por Robin na introdução de uma tarefa de linguagem, que era recontar aspectos da estória de Parahika. Era interessante que ela usasse um instrumento visual para ensinar as crianças a acharem o foco na linguagem escrita: as lentes! Continuamos a exploração com a tinta, usando as habilidades previamente adquiridas com a mistura de cores, e amplificamos o estado metafórico através de contato com o sonho visionário de Te Whiti na estória de Parahaka. Nisso fomos auxiliados pelo livro de Dick Scott (1975) e pelas pinturas Parihaka do artista contemporâneo Maori, Sclwyn Muru, através do vídeo e slides de Renwick (1987). As crianças receberam papéis grandes e foram convidadas a pintar Uma terra que vale proteger e um céu para sonhar, misturando tinta acrílica, usando os dedos e, mais tarde, pincéis.

A pintura inicial foi reconhecida como a base (não um fundo) sobre a qual nós iríamos, mais tarde, "sonhar". Assim que isso terminou, um exercício de visualização dirigida com o objetivo de focar as imagens pessoais trouxe, claramente, à tona empecilhos importantes encontrados com frequência no trabalho imaginativo.

Eram clichês, cópias, resultantes da falta de confiança na própria imagem ou na própria habilidade, e produçóes para satisfazer ao professor. A criança, que se viu diante de uma ideia ou imagem que parecia muito difícil ou muito mundana para pintar, possivelmente, ajustava sua ideia a uma menos desafiadora, menos autêntica. As crianças foram encorajadas a ficar com suas primeiras imagens, não burlá-las ou dissipar a energia falando sobre elas. Elas foram solicitadas a procurar 
um objeto ou fotografia que desse suporte às suas ideias. Entre os objetos protetores especiais "encontrados", nós tivemos inúmeros "cristais fosforescentes", das meninas, e "armas diversas", dos meninos. O inconsciente é uma mistura tão vulgar de clichês e eu estava, a duras penas, tentando evitar a coleção de bolas cósmicas fofas da fantasia artística new age. Assim, encarando o problema de frente, eu continuava encorajando as crianças a respeitar a primeira imagem que havia surgido para elas e trazê-la à realidade da maneira mais rica possível, prestando atenção à sua forma, enfatizando o que acontece à sua volta em termos de cor e tonalidade.

Nesse ponto começamos, finalmente, a passar para as crianças a responsabilidade de selecionar e desenvolver as imagens. Meu papel como orientador técnico, mais do que manipulador de imagens, estava agora claramente evidenciado. Robin conversou muito intensamente com Phillipa, que havia mudado sua ideia para pintar algo semelhante ao de sua vizinha Katherine. Robin insistiu, encorajando Phillipa a acreditar no valor de conservar sua própria imagem, justamente porque era a sua.

Usando a coleção de portais e entradas Maori do Otago Museum e cenas de vídeo do artista Maori Cliff Whiting, começamos a fazer relações mostrando como as construções na arte Maori contavam estórias, que eram histórias importantes do seu povo. Como a sala tinha a possibilidade de ter um Arco Memorial, decidimos encontrar imagens que nos fizessem sentir mais fortes, mais nós mesmos, na nossa classe. Eu estava preocupado em não reduzir o tema subjacente ao que encontramos nas Whare Whakairo (Casa Maori de reunião), imitando os padrôes Koru (o clichê neozelandês das aulas dos anos de 1990, que desalojou o desenho de observação do sapato dos anos de 1980 . Eu suspeito que a Austrália tenha desenvolvido uma erupção de pinturas pontilhadas, que deve pouco à arte aborígine e nada a Seraut e Signac).

As crianças eram desafiadas a refletir sobre o que era verdadeiramente importante para elas, colher qualquer recurso visual que julgassem necessário, rascunhar algumas ideias, escolher o tamanho e a forma do papel, selecionar sua própria paleta de cores e pintar, sabendo que sua pintura iria juntar-se a dos outros para formar o nosso Arco das Memórias.

Eu estava ansioso. Teria despejado muita responsabilidade sobre elas tão rapidamente? Elas iriam se desencorajar ou iriam propor, para 
elas mesmas, tarefas facilmente realizáveis? Elas iriam correr para pegar papéis gigantes, porque quanto maior melhor? Há um momento em qualquer esforço criativo, seja qual for o nível de desenvolvimento, quando o aprendiz tem que entrar num domínio, a partir do qual o professor pode acompanhar apenas de longe. $\mathrm{O}$ aprendizado real é solitário, mas não abandonado. Meu papel, nesse momento, mudou para um mais desafiante. Eu deixei bem claro como queria ser requisitado:

\footnotetext{
"Eu quero que vocês se responsabilizem por suas próprias ideias. Eu não quero ser aquele que diz: Faça isto, tente esta forma, sim, isto está ok!. A pessoa mais importante no trabalho de arte que você está fazendo é você. Você toma as decisões. Eu vou ajudar você a perceber quais são as suas perguntas. Qual é o seu foco? Qual o lugar, evento, pessoa, coisa que é importante para você? O que está acontecendo? Onde você está? Você está chegando lá? O que é realmente importante na sua pintura? Qual é o tamanho e a forma da sua ideia? Meu trabalho não é responder estas perguntas... este é o seu trabalho".
}

O clima emocional já estava instalado. Aquelas crianças haviam aprendido sobre uma cultura que valoriza a partilha de sentimentos e acontecimentos pessoais. Isso era seu alimento cotidiano em linguagem falada ou escrita, quando o superficial era desafiado e o foco ajustado, enquanto mantinham um clima de confiança. A classe foi instigada a considerar o que era mais importante para eles e por que. Um momento comovente aconteceu na discussão conduzida por Robin. Um menino, tranquilamente, disse que ia desenhar a perda da sua carteira cheia de dinheiro, mas mudou de ideia para desenhar Milo, seu Budgie (um tipo de periquito da Nova Zelândia), porque ele era... e ficou em silêncio. A professora foi sensível à exposição da criança e disse: "Foi por isso que você escolheu Milo... porque ele era? No silêncio que sucedeu a pergunta, todos ficaram com os sentimentos parcialmente expressos e um menino de 8 anos levantou-se e cruzou a sala para se colocar do lado do seu amigo. Esta é uma classe, onde um menino pode lamentar, abertamente, a morte do seu Budgie e onde um colega, jogador de rugby, pode cruzar o grupo para apoiar o luto do seu amigo. $\mathrm{O}$ grupo continuou tranquilamente a sua exploração, respeitando tanto os sentimentos compartilhados como os privados. A discussão seguiu, todos sabendo que cada um estava sendo cuidado. Esse é um clima cultivado. Isso emerge de uma professora que é totalmente 
disponível para ouvir, não tem medo dos sentimentos, respeita a privacidade dos alunos e é autêntica em suas respostas às crianças. Isso dá a elas confiança para serem autênticas em suas respostas.

Eu acredito que a autenticidade na arte é sua própria defensora. Emerge quando os professores são autênticos com as crianças. De fato, desejaríamos que todas as vozes a que as crianças estão expostas fossem autênticas, incluindo as de fontes vivas e as publicadas. Para mim, aquelas crianças conheceram não apenas a superfície de outra cultura, mas participaram da função e dos motivos que dão origem à criação da arte de outro grupo cultural. Se tomamos algo emprestado, foram as estruturas subjacentes e os temas. No encontro com outra cultura, aquelas crianças ficaram na posição de dizer: Estas são nossas estórias, nosso mundo - Conte-nos a sua.

As pinturas variaram em tamanho, desde uma pintura intimista em formato A4 de Milo, o Budgie, até uma de formato A1: um autoretrato da memória do primeiro ponto, marcado como primeiro lance, nesta temporada de rugby.

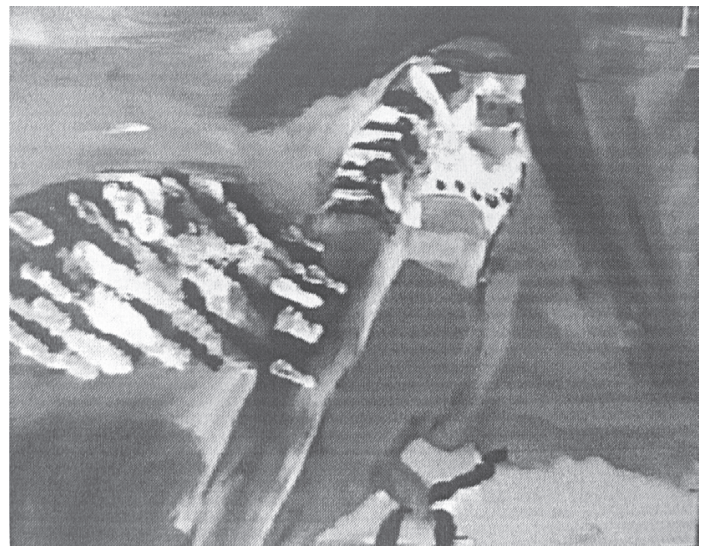

Curiosamente, quando as crianças escolhem sua própria escala, formato e tamanho dos pincéis, todos completam seus trabalhos dentro do tempo estipulado. Os trabalhos foram dispostos coletivamente, 
formando um arco perto da entrada da classe, tendo como suporte $o$ muro dos sentimentos.

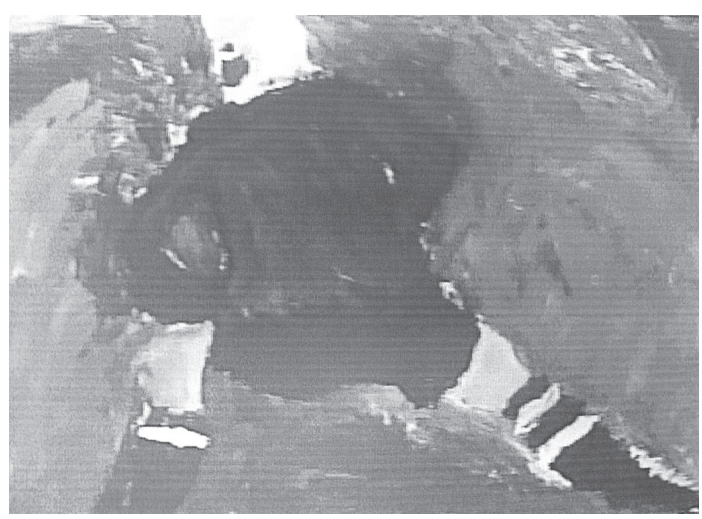

Nós chegamos "lá"? Como poderíamos saber? As crianças chegaram "lá"? Elas sabem onde chegaram? O que elas disseram? Elas contaram apenas o que pensavam que eu queria ouvir? Isto foi o que elas escreveram:

Eu entendo que arte pode...

Impressionar outras pessoas.

Mostrar as memórias e as ideias das pessoas.

Decorar lugares sem graça.

Contar estórias.

Lembrar coisas que são especiais.

Explorar sentimentos tristes e alegres.

Conservar coisas preciosas.

Fazer as pessoas famosas.

Educar professores.

Dar informaçôes para turistas.

Fazer as outras pessoas felizes.

Ser vista em museus.

Deshumbrar aspessoas. 
Eu sei como...

Pintar com os dedos.

Misturar cores.

Usar a memória e o olhar.

Tirar ideias dos livros, de outras pessoas e algumas vezes de mim mesmo.

Eu ainda gostaria de...

Fazer o roxo sair da minha pintura.

Fazer mais pinturas... a pedra Rongo com as espirais nela.

E elas fizeram mais pinturas? A resposta veio durante o estudo seguinte sobre a Antártica nos trabalhos que foram feitos, independentemente, por um grupo. A professora deu espaço e tempo para os alunos elegerem e perseguirem seus próprios focos. Suas escolhas e a forma como desenvolveram os temas são a pedra de toque, para mim, de como eles avançaram, aceitando responsabilidades, selecionando e desenvolvendo seus próprios temas e aproveitando a oportunidade de empregar, novamente, as habilidades que haviam adquirido.

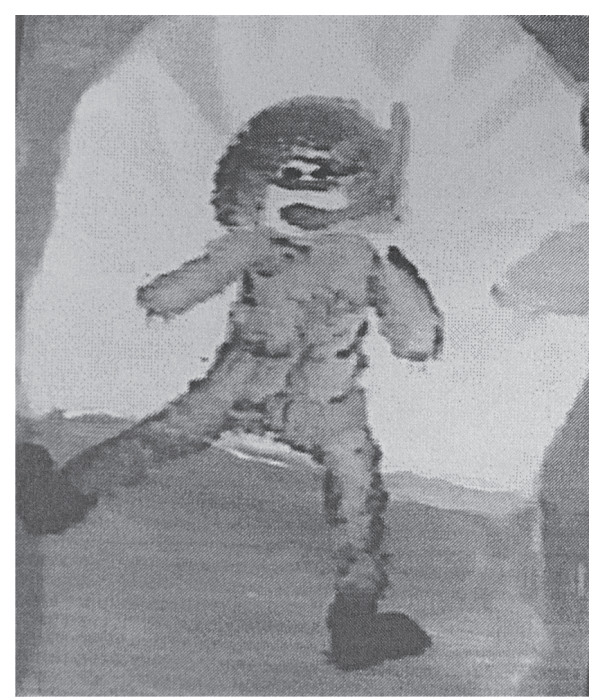


Em direção à autenticidade: encontro com a diferença
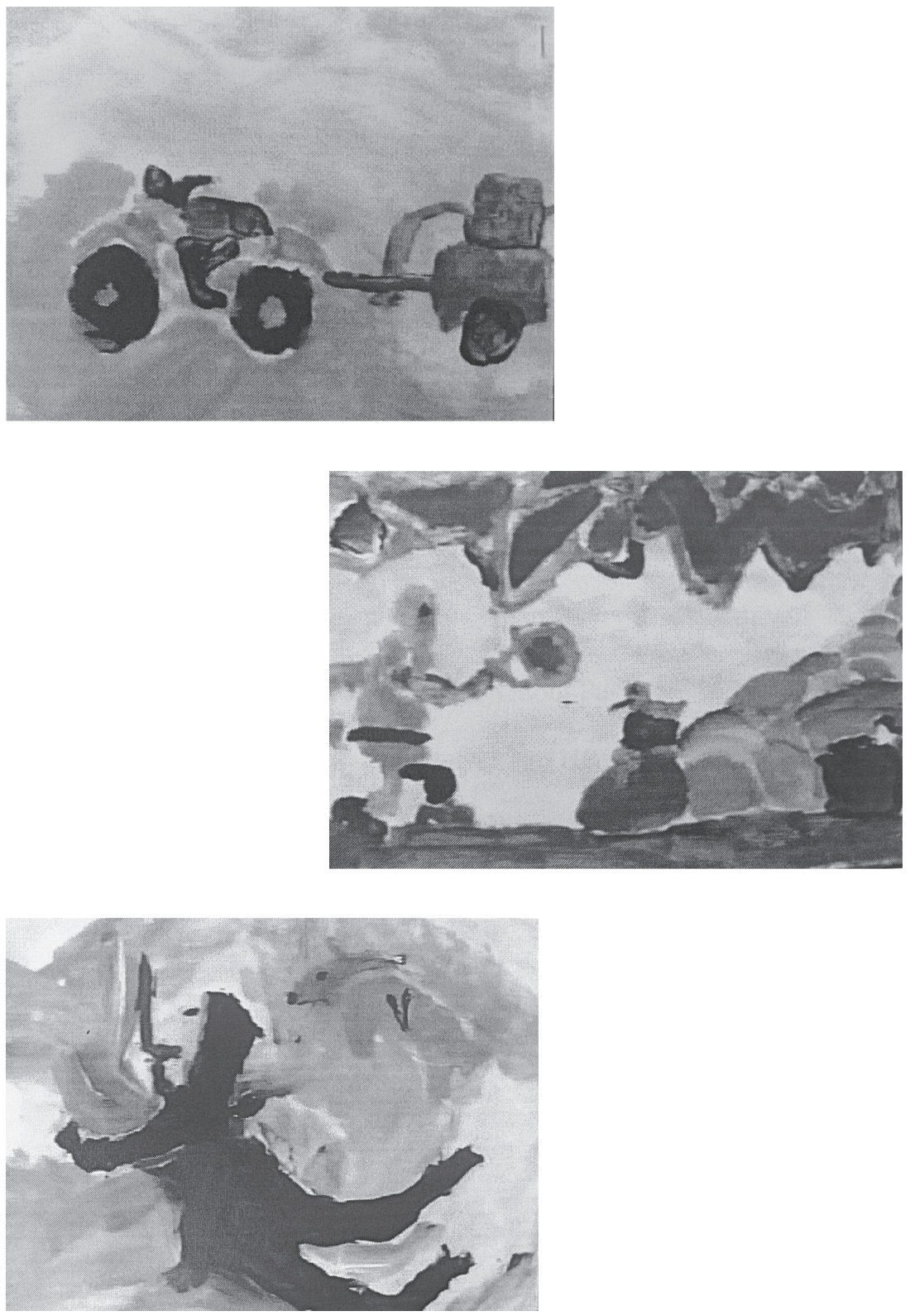
Termino com as palavras de Phillipa, que começou nossa unidade nervosa com suas próprias ideias, olhando para Katherine para se inspirar sobre como compor seu ponto de vista e sem confiança no desenho de suas figuras.

Eu posso fazer minha pintura melhor...

Fazendo-a mais leve

Dando beiradas crespas para as formas

Usando mais cores nas misturas

Concentrando-me e pensando mais sobre ela

Enão fazendo o que Katherine faz...

Recebido em julho de 2008 e aprovado em março de 2010.

\section{Nota}

1. Tradução livre de uma versão do inglês de conhecida canção Taranaki Maori: "Whakaronga ake au/ki te tangi a te manu/e rere runga rawa e/Tui tui tuia/tuia $\mathrm{i}$ runga/tuia $\mathrm{i}$ raro/tuia $\mathrm{i}$ roto/tuia i waho/tui tui tuia/ka rongo Te Pó/ka rongo Te Ao/tui tui tuia/Whakarongo au”.

\section{Referências}

DAVIS, F. Maori art and artists. Education. Wellington: School, 1976.

GRIFFITHS, G.; GOODALL, M. Maori Dunedin. Dunedin: Otago Heritage Books, 1980.

RENWICK, W. Emblems of identity. Wellington: vPU; Department of Education, 1987. [video/slide set].

SCOTT, D. Ask that mountain: the story of Parihaka. Auckland: Heineman, 1975. 